\title{
Labor management and social and labor relations in the digital economy ${ }^{a}$
}

\author{
Dmitry Desyatko ${ }^{1 *}$, Boris Genkin ${ }^{1}$, and Viktoriya Rapgof $^{2}$ \\ ${ }^{1}$ Saint Petersburg State University of Economics, Economics and Finance Faculty, 191023 Sadovaya \\ st. 21, Russian Federation \\ ${ }^{2}$ Saint Petersburg State University of Architecture and Civil Engineering, Faculty of economics and \\ management, 190005 2-ya Krasnoarmeiskaya st. 4, Russian Federation
}

\begin{abstract}
Social partnership is the most important type of social and labor relations in the modern economy, which is based on the active participation of trade unions in the enterprises management, payroll rate determination, and improvement of its conditions. In addition, in the framework of the conditions of extensive application of digital technologies the employees being outside the premises of the employer's organization began to perform a significant part of the functions of many organizations, and for a certain category of employees, the possibility of their replacement with intelligent machine systems will become the reality in the near future. The paper shows that one of the optimality criteria for the parameters of the social system is the country's living standards. The proposed criterion takes into account GDP per capita, the Gini ratio and the crime rate. The paper also shows that in the digital economy one of the main factors of the living standards growth is the application of new scientific results. The specific measures are proposed to create new forms of social and labor relations in the digital economy.
\end{abstract}

\section{Special aspects of labor management in the automated productions and management data processing systems}

Labor management systems are determined by the following basic concepts:

- human activity;

- workplace;

- labor rating.

Human activity is characterized by three components:

- regulated;

- creative;

- ethical [1].

\footnotetext{
${ }^{\mathrm{a}}$ This article was prepared under financial support of the Russian Science Foundation (Grant No. 1818-00099)

*Corresponding author: ddesyatko@yandex.ru
} 
The regulated component in the production systems is particularly presented on car assembly lines. Despite the use of robots, a part of the operations is performed by workers. In these productions, the need for automation based on the digital technologies is determined by economic and social factors.

The creative component is the basis for everybody who creates new scientific, technical, and entrepreneurial ideas. The human creativity becomes the main economic resource in the modern economy.

The ethical component of human activity in the production systems is especially important for managers at all levels. The teamwork effectiveness depends largely on them. The ethical aspects for using the digital technologies are largely based on the human employment prospects.

The concept of "workplace" has two aspects. The first aspect features a set of elements (equipment, tools, means of communication) that are necessary to perform a certain part of the production process. In this respect, the workplace can be individual or collective. The second aspect of the concept of "workplace" features a field of one employee. This aspect is used in the employment management systems and the labor market analysis.

In the framework of the conditions of extensive application of digital technologies the employees being outside the premises of the employer's organization began to perform a significant part of the functions of many organizations. To denote such employment, the terms "free", "remote", "home", "distance", etc. are used.

A considerable number of publications have been devoted to the problems of "remote" workplaces over recent years. It should be noted the paper [2], the authors of which pay attention to the importance of legally accurate definition of the nature of work on electronic platforms, so that working platforms will be provided with a special protection similar to part-time regulations, fixed conditions or agency work. In cases they are not qualified as employees, they should be protected as self-employed ones. Studies conducted under the auspices of the Eurofound 2015 [3] have showed that nine new forms of employment appeared from the beginning of the 21 st century, three of which are a direct consequence of the rapid development of digital technologies: ICT-based mobile operations where workers do not use their employer's premises as their main workplace and spend the most part of their time working with information and information technologies; employees can be hired or self-employed on the online platforms ("crowdsourcing of work"), which allows organizations or individuals to access to an uncertain and unknown group of other organizations (for example, PeoplePerHour, ClickWorker or Amazon Mechanical Turk) via the Internet; call-type work is characterized by continuous labor relations without continuous work, when the employer signs an employment agreement with the employee, but does not undertake to provide the work continuously (a zero contract is the most famous example of this phenomenon). The importance of changing the labor nature and the possibility of its replacement with intelligent machine systems is investigated in the papers $[4,5,6,7]$.

Labor rating is the most important part of labor management and remuneration. The paper [1] presents the importance and necessity of correct economic use of expenditure rates and results, duration rates and labor intensity of operations, other rate.

The process of comprehensive substantiation of labor standards, taking into account the interrelation of technical, economic and social factors, is implemented as the choice of the optimal variant of the rate and the relevant parameters of the technical and labor processes. 
The main objects of labor rating are the rates of duration and labor (operations) intensity:

$$
N_{T}=N_{D} \times N_{N}
$$

Where

$N_{T}$ - labor rate,

$N_{D}$-duration rate,

$N_{N}$-a rate of workers performing this operation.

The process operations duration rates are usually calculated using the formula:

$$
N_{D}=\left(t_{\mathrm{o}}+t_{b}\right)\left(1+\frac{K_{\mathrm{o}}+K_{r}}{100}\right)+\frac{T_{e}}{\mathrm{n}}
$$

where $t_{0}$ is the main (process) time; $t_{b}$ is an auxiliary time for parts installation and removal; $K_{o}$ is a workplace service time, $K_{r}$ is a rest and personal needs time factor; $T_{e}$ is an equipment setup time; $n$ is a size of the parts batch.

The process time $\left(t_{0}\right)$ is calculated based on the choice of a rational equipment operating mode. All other formula elements are determined by rates, which, as a rule, are established according to the statistics and do not have sufficient justification for the particular workshop conditions.

In the conditions of automated manufactures using computerized numerical control equipment, the operations duration calculation shall take into account, first of all, the planned level of automatic operation of equipment. This level determines the abilities to implement the output program.

If the direct costs of products include only the costs of the main (machine, hardware) time, then:

$$
N_{d}=t_{\mathrm{o}} \frac{T_{s}}{T_{s}-T_{b}}
$$

where $t_{0}$ is a machine (hardware) time per a product unit; $T_{s}$ is a working shift duration; $T_{b}$ is a scheduled and accident ${ }^{\mathrm{b}}$ breaks in equipment operation per shift.

A rate for a number of employees maintaining the automated equipment shall be calculated based on the standards of labour intensity of the scheduled breaks for equipment repair and setup. When calculating the rates for a number of employees maintaining the automated equipment, the probability of accidental equipment failures shall also be taken into account. The tables based on the queuing theory [1] are proposed for practical calculations.

\section{Special aspects of social and labor relations in the digital economy}

The social and labor relations feature the economic, psychological and legal interrelationships between individuals and social groups based on the labor activity

Social partnership is the most important type of social and labor relations in the modern economy, which is based on the active participation of trade unions in the enterprises management, payroll rate determination, and improvement of its conditions. The main ideas

\footnotetext{
${ }^{\mathrm{b}}$ Caused by equipment failure
} 
of social partnership were developed and implemented by a group of German economists under the guidance of L. Erhard [8].

The social system, where private ownership of the production means and market pricing remains, is commonly called a socially oriented market economy [9].

The progressive scale of personal taxes that allows significantly reduce the economic inequality of the country's population plays an important role in this system of public relations. Health care and pension system management also contributes the reduction of inequality.

The elements of capitalism and socialism are combined in the socially oriented market economy.

This confirms the validity of the Hegel's triads: thesis $\rightarrow$ antithesis $\rightarrow$ synthesis. In this case, this triad is specified in the form: capitalism $\rightarrow$ socialism $\rightarrow$ market economy and social partnership.

Based on the idea of social partnership, which is the basis of social and labor relations in the modern economy, we can formulate the task to choose the optimal structure of the social system parameters.

The criterion of optimality in this task is the country's living standards. The constraint system includes the characteristics of the country's resources and the conditions for their most effective use.

Thus, the following parameters shall be determined:

$$
X=\left\{x_{1}, x_{2} \ldots x_{n}\right\},
$$

under which

$$
K_{\mathrm{x}}=\frac{\text { Actual levels of goods consumption }}{\text { Needs of the population }} \rightarrow \max
$$

and the following limits are observed:

- legal rules;

- available resources;

- personal income differentiation degree;

- environmental standards;

- other parameters.

where $X=\left\{x_{1}, x_{2} \ldots x_{n}\right\}$, - the set of analyzed parameters of the social system; $K_{x}-$ the living standards depending on $X$.

In the digital economy one of the main factors of the living standards growth is the application of new scientific results.

In modern Russia, a share of GDP research costs is a little higher than $1 \%$, which is significantly less than in developed and many developing countries. Therefore, one of the conditions (limits) of the problem under consideration shall be the following relationship:

$$
R \& D(X) \geq 0.02 G D P
$$

where $\mathrm{R} \& \mathrm{D}(\mathrm{X})$ is a share of science costs in GDP.

As shown in [8], the main indicators of the country's living standard are the following:

- GDP per capita $\left(\mathrm{G}_{\mathrm{p}}\right)$;

- Level of income differentiation(D);

- Crime rate (C). 
Therefore, the objective functions that meet the criteria for the optimality of the social system parameters are:

$$
\begin{aligned}
& \mathrm{G}_{\mathrm{p}}(\mathrm{X}) \rightarrow \max ; \\
& \mathrm{D}(\mathrm{X}) \rightarrow \min ; \\
& \mathrm{C}(\mathrm{X}) \rightarrow \text { min. }
\end{aligned}
$$

where $G_{p}(X)$ - gross domestic product per capita; $D(X)$ - income differences factor; $C(X)$ crime rates.

Our earlier studies [9] allowed us to determine the living standard indicators for developed and some developing countries. The highest living standard indicators are in countries where the idea of the socially-oriented market economy has been implemented (Iceland, Sweden, Finland, Denmark, Netherlands, Japan, Germany), where the average rating for the three above-mentioned indicators ranges from 9.7 to 22.3 points. Indicators of the US and Russia are significantly worse because of high levels of income and crime differentiation (69.7 and 78.3, respectively).

In the same study, it was shown that for a sample that includes the developed countries of Europe, the United States and Russia, a correlation number between the income and crime differentiation rates is more than 0.95. High levels of crime in the US and Russia are largely due to the fact that income differentiation rates in these countries are 2 times higher than in developed countries of Europe, including Sweden, Norway, Denmark and Germany.

One of the most important aspects of social and labor relations is the ratio of productivity and wage, taking into account the personal income differentiation.

As seen from Fig. 1, 2, the dynamics of wage levels in developed countries generally corresponds to the dynamics of productivity.

When analyzing the ratio of productivity and wage, it is necessary to proceed from the fact that the growth rates of wage of farmers, workers, engineers, artists, writers can not objectively outstrips the growth rates of their labor productivity.

The higher is the hierarchy level, the less noticeable is the relationship between the levels of productivity and wage. This fact is illustrated in Fig. 5 which combines the information of Fig. 3 and 4.

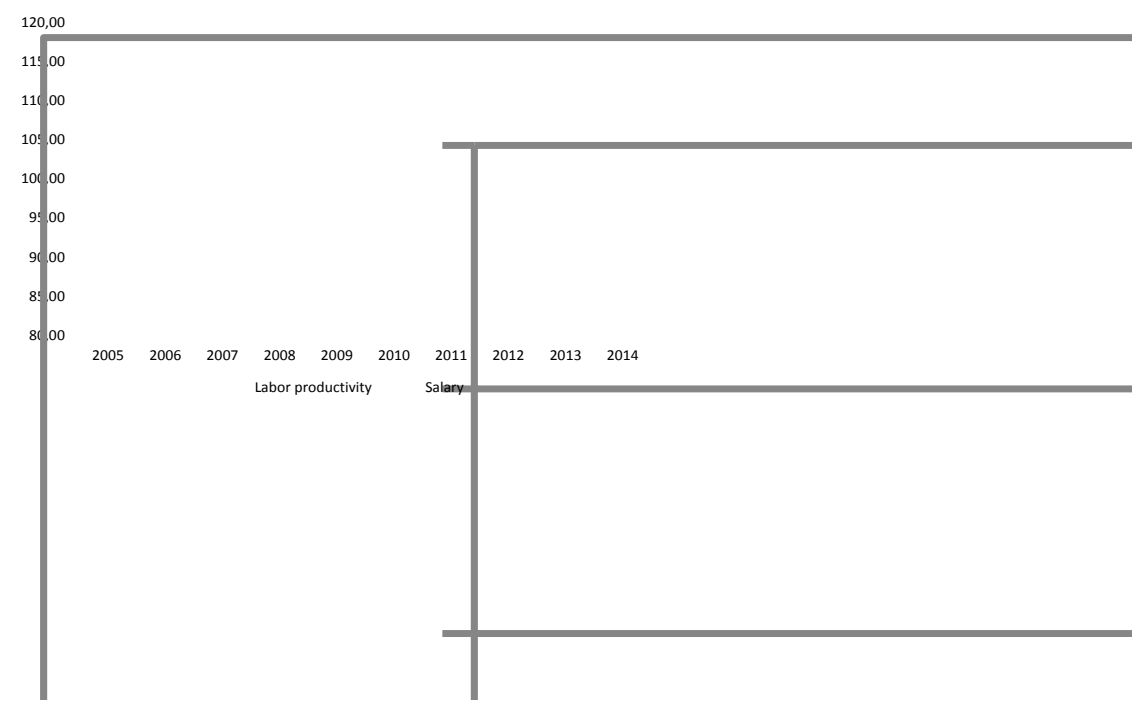

Fig. 1. The dynamics of labor productivity and wage in France, 2005-2014. 


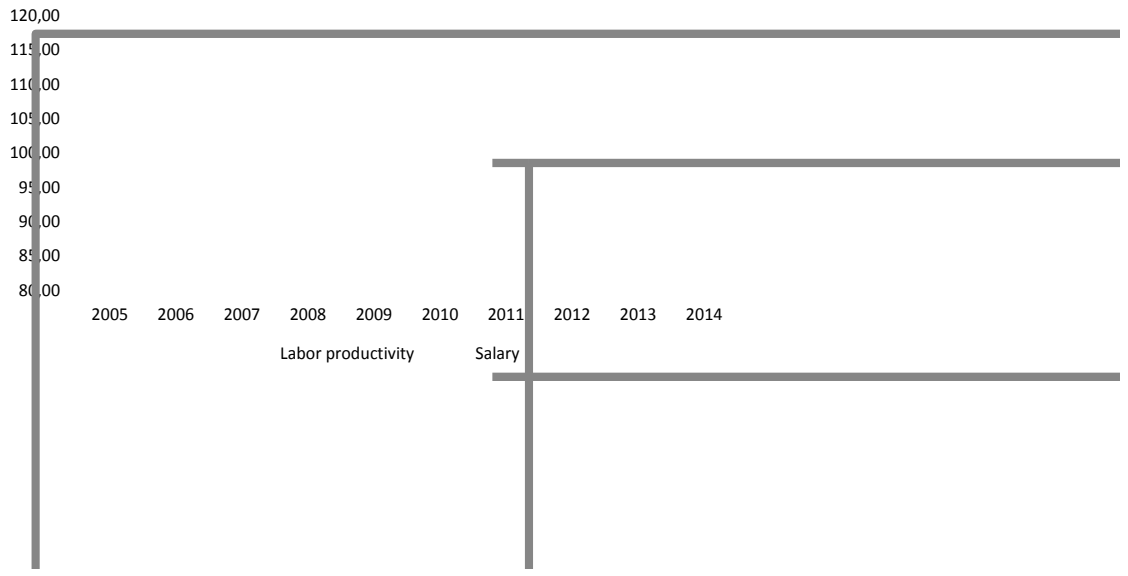

Fig. 2. Dynamics of labor productivity and wage in Finland, 2005-2014.

The growth rate of wage in Russia outstrips the growth rates of labor productivity (Fig. 3). The main reasons for this ratio are the following:

- Russia's lag in productivity of labor from developed countries is 2-3 times [10];

- a high degree of personal income differentiation.

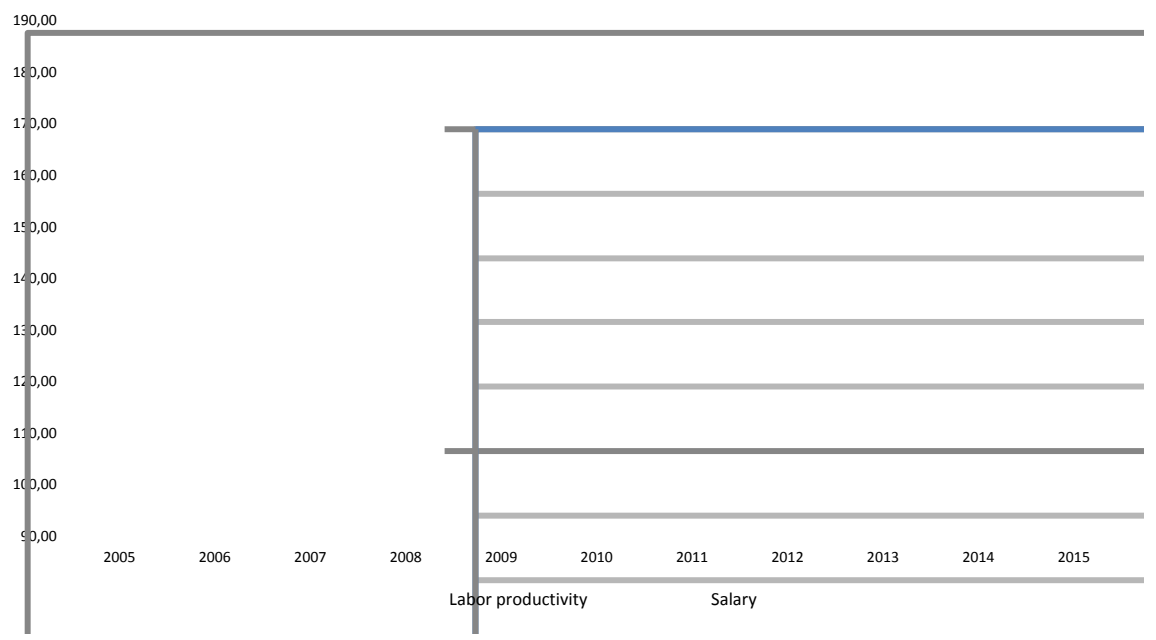

Fig. 3. Dynamics of labor productivity and wage in Russia, 2005-2015. 
Fig. 4 shows the dynamics of personal income levels in five groups (quintiles).

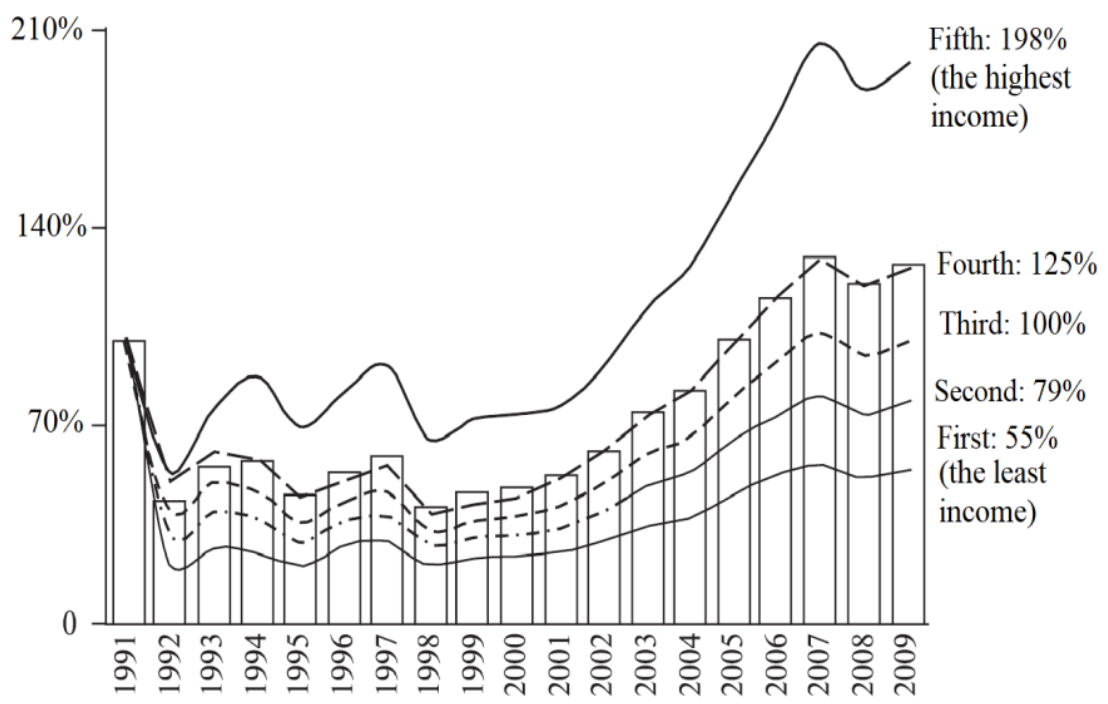

Fig. 4. Dynamics of real money personal income in Russia by $20 \%$ income groups [11].

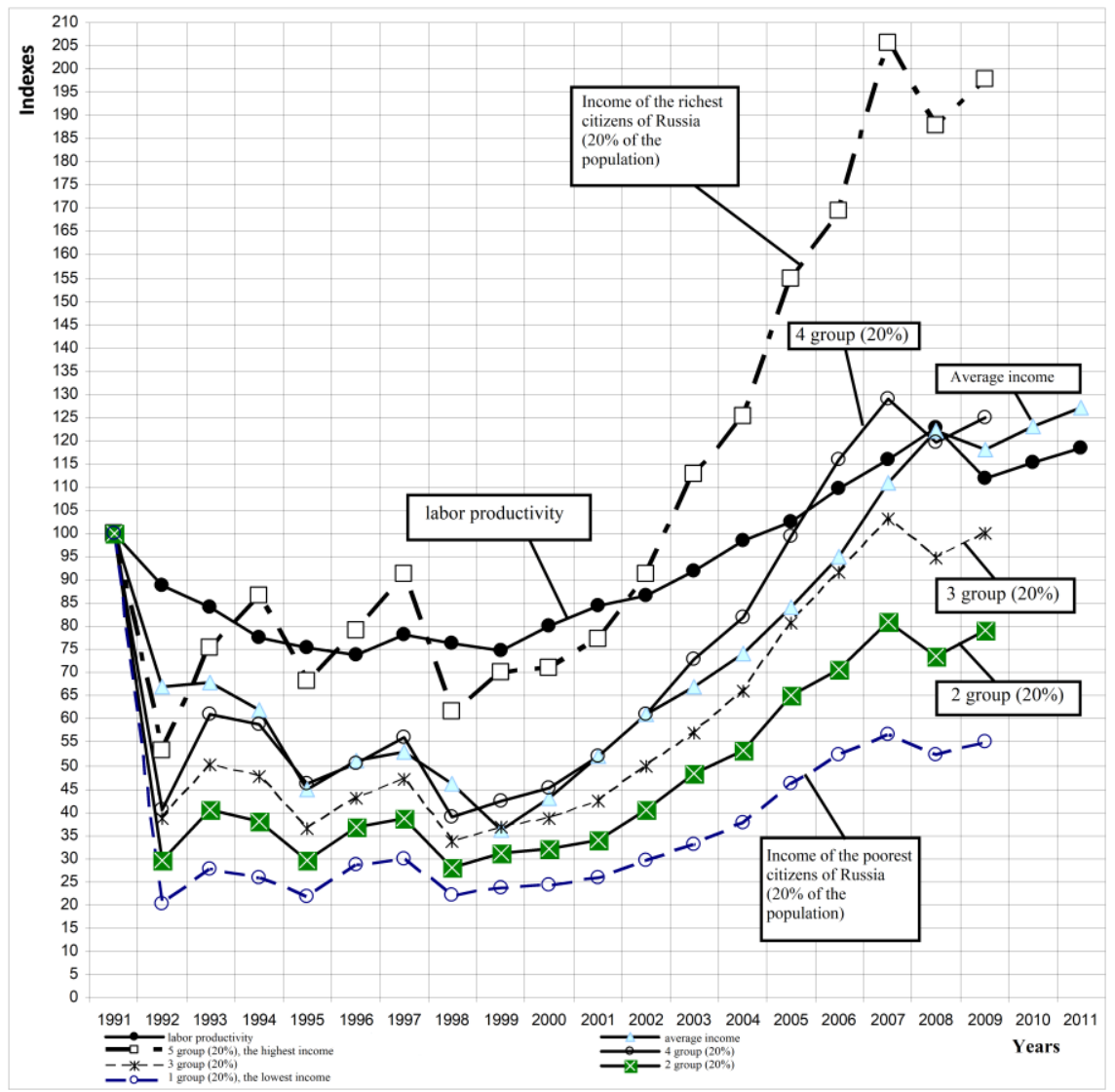

Fig. 5. Dynamics of labor productivity and real money personal income in Russia by $20 \%$ income groups [11]. 
As seen from Fig. 5, for the richest $20 \%$ of the Russian population, the income growth rate is much higher than the growth rate of labor productivity.

We fully admit that among the richest citizens of Russia (5th quintiles) there are outstanding inventors and businessmen, whose incomes correspond to the results of their labor. But it is clear that such representatives of business are not very many.

More than three years ago, a system of performance-based contracts was introduced in the budgetary organizations of Russia (schools, universities, regulatory bodies), which establish the relationship between the employees performance of the organization and the bonuses level.

Accounting of officials' performance is much more difficult than assessing the importance of publications by an associate professor or professor. An objective assessment of management efficiency of economic and social processes at various levels of the administrative hierarchy shall be based on the assessment of a large amount of statistical information. This supposes the use of modern means of data collection and processing, which allow arranging the accounting of personal incomes for all sources.

To improve social and labor relations in modern Russia, we introduced a proposal on the adoption of the Law "On the motivation of productivity growth and remuneration based on innovation and social partnership" [1]:

1. The motivation of labor productivity and wage growth is carried out by regions and sectors of the economy.

2. The minimum wage in a region shall be no less than the regional subsistence minimum wage.

3. In all organizations of the region's commercial sector, the minimum wage (MW) shall increase annually in accordance with the growth rate of labor productivity in the relevant sector of the region and the level of inflation in the past year.

4. The average wage of workers and employees of enterprises (without the income of members of the boards of directors) shall be no less than three times the minimum wage at the enterprise.

5. The relationship between the growth rates of productivity and the minimum wage is established as a result of negotiations between representatives of employers, trade unions and the government of the region.

6. In the non-profit sector and regional authorities, the growth of the minimum wage shall correspond to the average growth in labor productivity in the region and the level of inflation in the past year.

The proposed scheme for managing productivity and wages does not use any internal information of enterprises. They are considered as "black boxes" and transmit to the management bodies only the usual statistical information on the products output and a personnel number. On the basis of these data, the indicator of the average labor productivity in the economy branch and on the region as a whole is determined.

Similar ideas are expressed in those countries of Western Europe, where the processes of economy digitalization are very fast. Therefore, one of the largest German trade union amalgamation IG Metall [4] deserves attention: they are aimed at guaranteeing the social rights of workers in the digital world: development of new coding forms for the digital world, adaptation and protection of cognitive law; development and implementation of comprehensive rules for mobile workers; definition of the rights to participate and protect when working on the basis of electronic platforms; increase the level of employees' data protection; development of approaches based on the concept of humane digital workplace; development of the competence of officials working part-time; encouraging public debate that influences research policy; development of standards for occupational safety and health; more active efforts to promote learning at the company level; use of new methods of training in the ICT workplace and certification of skills acquired at the workplace. 
Adoption of the proposed law and proposals from German trade unions fully corresponds to the ideology of social partnership, which is the basis of social and labor relations.

\section{References}

1. B.M. Genkin, Arrangement, rating and remuneration of labor at industrial enterprises, (Norma, Moscow, 2014)

2. J. Drahokoupil, B. Fabo, European Economic, Employment and Social Policy, 5, 6 (2016)

3. Eurofound, New forms of employment (Publication Office of the European Union, Luxembourg, 2015)

4. E. Brynjolfsson, A. McAfee, The second machine age. Work, progress and prosperity in a time of brilliant technologies (W. W. Norton \& Company, New York, 2015)

5. C. Degryse, Digitalization of the economy and its impact on labour markets (ETUI, Brussels, 2016)

6. EU-OSHA, A review of the future of work: robotics (European Agency for Safety and Health at Work, Bilbo, 2015)

7. C. Fuchs, E. Fisher, Reconsidering value and labour in the digital age (dynamics of virtual work series (Palgrave Macmillan, Basingstoke, 2015)

8. L. Erhard, Half a Century of Reflection (Russiko, Moscow, 1993)

9. B.M. Genkin, D.N. Desyatko, E.A. Ekimova, Living standard in Russian regions, 4 (2016)

10. S.Yu. Glaziev, Russia is on the way to the innovative economy (RAS Report, 2014)

11. E.G. Yasin, The level and lifestyle of the population of Russia in 1989-2009 (Publ. House VShE, Moscow, 2011) 